\title{
Research on the Problems and Countermeasures of Deep Cooperation between Universities and Enterprises in Higher Education
}

\author{
Yanfen Gan ${ }^{a}$, Yanyan Lin ${ }^{b}$ \\ School of information science and technology, South China Business College Guangdong \\ University of Foreign Studies, Guangzhou, 510540, China \\ aFannygyf@foxmail.com, b25037577@qq.com
}

\begin{abstract}
With the continuous reform of subject education in colleges and universities and the deepening development of University-enterprise cooperation, deep University-enterprise cooperation has new characteristics. However, the policy and management mechanism of University-enterprise cooperation is not perfect. The realistic obstacles of the University-enterprise teacher community and the integration mode of University-enterprise resources become the critical issues in the in-depth cooperation. This paper analyzes the main problems existing in the deep cooperation between universities and enterprises. It proposes solutions to the problems encountered in the cooperation, such as educational ideas, policies and regulations, and resource integration.
\end{abstract}

Keywords: University-enterprise Cooperation; Resource Integration; Teacher Community; Educational Ideas.

\section{Background of Deep Cooperation between University and Enterprise}

University-enterprise cooperation focuses on current vocational education reform and development and the difficulty of vocational education reform and development. It is the breakthrough and key point to solve many problems in current vocational education. The Outline of The National Medium - and Long-term Education Reform and Development Program (2010-2020) proposes establishing and improving a government-led, industry-guided, enterprise-participated school-running mechanism and formulating policies and regulations to promote University-enterprise cooperation. The deep cooperation between universities and enterprises is relative to the shallow cooperation between universities and enterprises. It mainly refers to the cooperation between universities and enterprises as not only a "result" cooperation but also a "process" cooperation, forming a positive and mutually beneficial relationship between universities and enterprises.

On the one hand, the deep University-enterprise cooperation will lengthen the chain of Universityenterprise cooperation, and on the other hand, expand the scope of University-enterprise cooperation. The contact points of both sides will increase, mutual dependence will also be enhanced, and the degree of cooperation will be naturally deepened. Of course, the deep cooperation between universities and enterprises is also on the premise that the cooperation mode should be adapted to the actual situation of the industry and enterprises.

There are many ways of deep University-enterprise cooperation [1]. In terms of school-running forms, such as "order" training, joint school-running between vocational universities and enterprises, collectivization of vocational education, etc. In terms of the construction of teaching staff, such as hiring enterprises and institutions of engineering and technical personnel, management personnel and special skills to colleges and universities as part-time teachers, teachers to the enterprise "postpractice", cooperative research, squatting survey and so on; In terms of teaching, according to the real working process of industrial posts and their requirements, to construct curriculum system and reform curriculum content in higher vocational colleges, to follow the rules of the formation of vocational post skills, and to implement integrated teaching of "teaching, learning and doing" and so on. 


\section{Analysis of Problems of University-enterprise Cooperation in Colleges and Universities}

The deep cooperation between universities and enterprises in higher vocational education has become a bottleneck for further reform and development of higher education and improvement of education quality. The main problems that seriously disturb the sustainable and healthy development of deep cooperation between university and enterprises in higher vocational education are as follows:

\subsection{Policy and Management Mechanism of Deep Cooperation between Universities and Enterprises}

The policy is the institutional guarantee of University-enterprise cooperative education in colleges and universities. Establishing a scientific and perfect University-enterprise cooperative education policy and the system is the key work of all levels of government, higher vocational colleges, and enterprises at present and even in the future for a long time. Although our country now attaches great importance to University-enterprise cooperation education in higher vocational colleges and has established University-enterprise cooperation associations and carried out large-scale pilot and experiments, the authoritative and complete University-enterprise cooperation standards and guidance manuals have not been established. The government has yet to come up with a reward mechanism for University-enterprise cooperation. There is insufficient protection of enterprise interests in University-enterprise cooperation. There is no special coordination organization for University-enterprise cooperation to supervise, assess, and carry out University-enterprise cooperation. Many projects are difficult to obtain sufficient support from the enterprise's competent units, labor departments, and education departments.

\subsection{Practical Obstacles of University-enterprise Teacher Community}

Due to different systems and mechanisms, educational concepts, and talents training concerns, universities and enterprises do not adapt to each other. The most direct reflection is that they cannot fully connect with teachers, resulting in disconnection [2]. First, there is no subordinate relationship between enterprise personnel and vocational colleges. The universities lack incentive and restraint mechanisms and professional development planning for part-time enterprise teachers. As a result, enterprise personnel lack a sense of belonging and responsibility to the school, and Universityenterprise teachers do not form a "community of destiny." Secondly, the school-running mechanism of vocational colleges is fixed, and the source of funds is single. The role and influence of the market and enterprises are generally ignored. The major setting of most vocational colleges fails to meet the needs of the market and enterprises. Universities enrollment and enterprise employment are separated. And specialty construction is operated only according to the level of universities teachers and resource allocation, which does not match the regional industrial development. Universities and enterprise personnel lack common cooperation direction and field in talent cultivation.

\subsection{Problems of University-industry Resource Integration Model}

The two sides of the universities and the enterprise use their respective resource advantages to sign a joint talent training agreement. The enterprise puts forward the requirements of talent demand specifications and specialty settings according to its production equipment and technical personnel. The two sides of the universities and enterprise jointly formulate training programs and teaching plans and introduce enterprise culture, production technology, production operations, and other teaching contents.

The universities is responsible for the teaching of students' basic theory courses and specialized basic courses. Students go to enterprises for practical teaching and skill operation. Enterprises participate in the whole process of talent training, and the education and teaching content of University-enterprise joint talent training runs through every teaching link. 
The education and teaching content of University-enterprise joint talent training runs through every teaching link. How to integrate University-enterprise resources to jointly train talents, how to measure whether the major setting connects with the job groups of the industry and enterprises, and how to connect the curriculum system with the job standards, so that students can work directly after graduation and become skilled technical talents is a very important issue [3].

\section{Literature Countermeasures Analysis of the Problems Arising from the Deep Cooperation between University and Enterprises}

\subsection{Policy and Management Mechanism Analysis of Deep Cooperation between University and Enterprise}

First, relevant departments need to improve the relevant laws and regulations of Universityenterprise cooperation education and guarantee the long-term development of University-enterprise cooperation from the institutional point of view. The government should revise, supplement, and improve the existing laws and regulations as soon as possible to formulate feasible measures supporting laws and regulations and strengthen the implementation and supervision. Second, we need to improve the relevant policy system, guide and encourage University-enterprise cooperation. Governments at all levels should actively play their own functions, formulate and improve relevant policy systems, and guide and promote University-enterprise cooperation in finance, taxation, credit, incentive policies, intellectual property rights, and other aspects to mobilize enterprise resources to serve universities teaching effectively. Third, we will improve the system for running universities in higher vocational education. We will deepen the reform of the government's management system for vocational education. The government should further clarify the school-running system of "government-led, relying on enterprises, giving full play to industry, participation of social forces, and joint development of public and private sectors" to actively attract social forces to participate in school-running. We will improve the government investment system and support industry-run, enterprise-run, and private colleges and universities.

\subsection{Analysis on Countermeasures of Realistic Obstacles to the University-enterprise Teacher Community}

The universities formulated and improved the management measures for part-time teachers and included them in the university's teacher training and development system [4]. Part-time teachers are managed at two levels, one is under the overall planning of the universities, while the secondary universities are responsible for daily management. The second-level colleges make training plans and menus for part-time teachers in combination with professional characteristics, including higher education laws and regulations, teachers' ethics, educational theories, teaching methods, teaching ability, modern educational technology ability, etc., to improve the implementation ability of parttime teachers to integrate quality education into professional education. The second level college is responsible for daily management. The second-level college makes training plans and menus for parttime teachers based on professional characteristics. The training contents include higher education laws and regulations, teachers' ethics, educational theories, teaching methods, teaching ability, modern educational technology ability, etc. Improving part-time teachers' ability to integrate quality education into professional education; Reasonable arrangement of part-time teachers to teach professional courses, the teaching proportion should reach $30 \%$ of the total professional hours; Appropriately raise the standard of teaching remuneration, encourage part-time teachers to participate in the construction of universities related projects in the form of project cooperation, and pay remuneration by the agreed content of the project agreement; We will explore ways to recognize the qualifications of part-time teachers, assess their professional skills, and even assess their professional titles, and formulate a treatment and promotion system for highly skilled personnel in university and enterprises. The universities and enterprise jointly carry out comprehensive assessments on part-time 
teachers every year. The universities will issue performance awards to outstanding part-time teachers. The assessment efficiency should be strengthened, and the annual assessment and evaluation of parttime teachers should be recorded in personal information files to improve their participation and sense of responsibility.

\subsection{Analysis on Countermeasures of University-enterprise Resource Integration Mode}

To do comprehensive cooperation between colleges, must strengthen vocational colleges and enterprises on the connotation of the docking work to guarantee the University-enterprise cooperation into practice, is truly achieve joint between colleges cultivate talents, improve the efficiency of enterprise production and reduce the cost of purpose. As a result, institutions of higher learning and enterprises should be in the following link to do a good job of "docking."

To measure whether the professional setting is really connected with the industry and enterprise post groups, on the one hand, it is reflected in the degree to which the major setting meets social needs and industrial transformation and upgrading. On the other hand, it is ultimately determined by the employment rate of students' majors. A professional setting is just like the product of an enterprise. First, there must be market demand; otherwise, there will be no market no matter how Radiation industry enterprises to study the professional post further, especially must pay attention to each of the professional technical post group, technical type of work and technical certificate content, such as dynamic master the enterprise condition of choose and employ persons and professional post changes, both want to consider the stability of the specialties and want to consider the flexibility of professional group of changes in the industrial enterprises. To realize the effective docking of University-enterprise cooperation in specialty setting and industry post group, and improve the contribution rate and serviceability of colleges and universities to local economic development.

University-enterprise cooperation is ultimately reflected in the connection between the curriculum system and the professional standards of the post. That is the key link to realize the zero-distance connection between students' professional ability and the enterprise's professional ability [5]. The standard vocational content required by the enterprise's post is replaced in advance with the curriculum system of the school's talent cultivation, the school's practical teaching content is replaced with the production, operation, and management links of the enterprise, and the University-enterprise "curriculum replacement" is carried out according to the enterprise's talent demand specifications and the vocational ability standards required by the post. By connecting the curriculum system with professional standards, University-enterprise cooperation finally becomes a reality. It forms a new talent training model featuring University-enterprise cooperation, resource sharing, complementary advantages, and win-win benefits. It forms a new personnel training mode featuring Universityenterprise collaboration, resource sharing, complementary advantages, and win-win benefits.

Engineering and technical personnel of enterprises undertake practical teaching tasks of cooperative vocational colleges, jointly develop practical teaching curriculum contents with teachers, and take charge of students' skill training and guidance. Teachers of vocational colleges take part in technological innovation, equipment transformation and research and development of new products of enterprises and undertake the training of continuing education of employees of enterprises. Teachers of specialized courses will go to cooperative enterprises for on-the-job practice. In terms of connotation, a two-way communication and flow mechanism should be established between vocational college teachers and enterprise engineering and technical personnel to improve the practical ability of vocational college students and the comprehensive quality of enterprise employees.

Anyway, profound cooperation of University-enterprise is an important measure of the two sides to carry out the scientific outlook on development and cultivate applied high skill talented persons. It enhances the connotation of higher learning institutions, highlights characteristics in colleges and universities, the important way to promote the development of higher education, is the realization of the government, university, enterprises an advanced educational mode of sharing the interests of all parties. At present, while exploring and practicing the new way of deep University-enterprise cooperation, colleges and universities should improve the laws and regulations about University- 
enterprise cooperation. Universities and enterprises should jointly build teachers, share resources, together promote the sustainable development of the deep cooperation between universities and enterprises in China's higher education, strive to create a new situation of higher education to cultivate high-quality applied high-skilled personnel, and make due contributions to serve the local economic construction better.

\section{Acknowledgments}

This work is support by Guangdong Provincial Undergraduate Teaching Quality and Teaching Reform Engineering Construction Project 2020 ([2020] No. 19) -- (Practice Teaching Base of South China Business College Guangdong University of Foreign Studies and Guangzhou Tenco Network Technology Co., Ltd.).

\section{References}

[1] Hong Zhenyin. Some Problems and Thoughts on the Deep Cooperation between Universities and enterprises in Higher Vocational Education [J]. Vocational Education Forum, 2010(16):57.

[2] He Yizhang. Analysis on The Construction Strategy of School-enterprise Teacher Community [J]. Journal of Taiyuan City Polytechnic college (8):3.

[3] Zhang Zhiqiang. Research on problems and Countermeasures of school-enterprise cooperation [J]. China Vocational and Technical Education, 2012, 000(004): p.62-66.

[4] Chen Ying. Review on school-enterprise Community and "Double-qualified" Teacher Team Construction [J]. China Training, 2019, 000(009): p.55-56.

[5] Zhang Cuiluo. Exploration on Deepening the Teaching Reform of "School-enterprise Cooperation and Integration of Industry and Education" [J]. Modern Enterprise,2021(09): p.144-145. 